\title{
Gestão de Organização Social e Acreditação no Sistema Único de Saúde (SUS): as implicações na saúde do trabalhador
}

\author{
Social Organization Management and Accreditation in the Unified Health System (SUS): the \\ implications for occupational health \\ Gestión de Organizaciones Sociales y Acreditación en el Sistema Único de Salud (SUS): las \\ implicaciones para la salud de los trabajadores
}

Recebido: 14/08/2021 | Revisado: 19/08/2021 | Aceito: 22/08/2021 | Publicado: 23/08/2021

\author{
Leiriane Alves de Souza \\ ORCID: https://orcid.org/0000-0002-0301-0189 \\ Universidade Federal de Uberlândia, Brasil \\ E-mail: leirilee@hotmail.com \\ Marisa Aparecida Elias \\ ORCID: https://orcid.org/0000-0002-9300-9519 \\ Universidade Federal de Uberlândia, Brasil \\ E-mail: marisaeliaspsi@gmail.com \\ Liliane Parreira Tannús Gontijo \\ ORCID: https://orcid.org/0000-0002-5762-1591 \\ Universidade Federal de Uberlândia, Brasil \\ E-mail: lilianetannus1@gmail.com
}

\begin{abstract}
Resumo
Os trabalhadores da saúde estão submetidos, usualmente, a condições precárias de trabalho, estresse e riscos ocupacionais. Em adição, houve a introdução de novas exigências da gestão pública, mediante Organização Social (OS), acompanhadas da implementação dos padrões de certificação de qualidade, sendo mais frequente, a acreditação. Esse estudo objetivou avaliar as implicações da gestão de OS e da acreditação, na saúde dos trabalhadores de uma unidade do Sistema Único de Saúde (SUS), sob a percepção dos mesmos e dos gestores. Utilizou-se da abordagem qualitativa, com suporte da analise temática de conteúdo. O estudo foi desenvolvido em uma unidade de saúde mista, da rede SUS municipal, administrada por OS e certificada pela acreditação. Utilizou-se as técnicas de grupo focal e entrevista individual, por amostragem intencional. Os resultados demostraram concordâncias entre gestores e trabalhadores concernentes aos benefícios da acreditação, entretanto revelam contrapontos no tocante às implicações na saúde do trabalhador. Nessa perspectiva, os trabalhadores relatam um agravamento à sua saúde e bem-estar, sobrecarga de atribuições e elevadas exigências de metas/indicadores, e ainda excessivos registros documentais, aspectos estes não reconhecidas pelos gestores. Ademais, trabalhadores afirmam que a gestão de OS conduz a: insegurança, ao receio de desligamento laboral, à baixa perspectiva de valorização, insatisfação profissional e adoecimento. Por conseguinte, é premente minimizar os efeitos prejudiciais à saúde dos trabalhadores, mediante a promoção de espaços de negociação democráticos, essenciais para tomadas de decisão equânimes, coparticipativas e efetivas na aplicação de medidas práticas de promoção e proteção à saúde do trabalhador, concomitante ao processo de acreditação.
\end{abstract}

Palavras-chave: Acreditação; Gestão em saúde; Política de saúde; Saúde do trabalhador.

\begin{abstract}
Health workers are usually subjected to precarious working conditions, stress and occupational hazards. In addition, there was the introduction of new requirements of public management, through Social Organization (OS), accompanied by the implementation of quality certification standards, with accreditation being more frequent. This study aimed to evaluate the implications of OS management and accreditation on the health of workers at a unit of the Unified Health System (SUS), under their and managers' perception. A qualitative approach was used, supported by thematic content analysis. The study was carried out in a mixed health unit of the municipal SUS network, administered by OS and certified by accreditation. Focus group and individual interview techniques were used, by intentional sampling. The results showed agreement between managers and workers regarding the benefits of accreditation, however, they reveal counterpoints regarding the implications for workers' health. From this perspective, workers report worsening of their health and well-being, overload of assignments and high demands for goals/indicators, and also excessive documentary records, aspects that are not recognized by managers. Furthermore, workers state that OS management leads to: insecurity, fear of job termination, low perspective of appreciation, professional dissatisfaction and illness. Therefore, it is imperative to minimize the harmful effects on workers' health, by promoting democratic negotiation spaces, essential for equitable, co-participatory and effective decision-making in the application of practical measures to
\end{abstract}


promote and protect workers' health, concomitant with the process of accreditation.

Keywords: Occupational health; Health policy; Health management; Accreditation.

\begin{abstract}
Resumen
Los trabajadores sanitarios suelen estar sometidos a condiciones laborales precarias, estrés y riesgos laborales. Además, se introdujeron nuevos requisitos de gestión pública, a través de Organización Social (OS), acompañados de la implementación de estándares de certificación de calidad, siendo la acreditación más frecuente. Este estudio tuvo como objetivo evaluar las implicaciones de la gestión de OS y acreditación de, en la salud de los trabajadores de una unidad del Sistema Único de Salud (SUS), bajo su percepción y la de los directivos. Se utilizó un enfoque cualitativo, apoyado por un análisis de contenido temático. El estudio se realizó en una unidad mixta de salud de la red municipal del SUS, administrada por OS y certificada por acreditación. Se utilizaron técnicas de entrevistas individuales y de grupos focales, mediante muestreo intencional. Los resultados mostraron acuerdo entre gerentes y trabajadores sobre los beneficios de la acreditación, sin embargo, revelan contrapuntos en cuanto a las implicaciones para la salud de los trabajadores. Desde esta perspectiva, los trabajadores reportan empeoramiento de su salud y bienestar, sobrecarga de asignaciones y alta exigencia de metas/indicadores, y también registros documentales excesivos, aspectos que no son reconocidos por los gerentes. Además, los trabajadores afirman que la gestión del OS conduce a: inseguridad, miedo al despido, baja perspectiva de apreciación, insatisfacción profesional y enfermedad. Por tanto, es imperativo minimizar los efectos nocivos sobre la salud de los trabajadores, promoviendo espacios democráticos de negociación, imprescindibles para la toma de decisiones equitativa, coparticipativa y eficaz en la aplicación de medidas prácticas de promoción y protección de la salud de los trabajadores, concomitantes con el proceso de acreditación.
\end{abstract}

Palabras clave: Salud laboral; Política de salud; Gestión em salud; Acreditación.

\title{
1. Introdução
}

O setor saúde se mostra bastante complexo, no que diz respeito a sua gestão, organização, fundamentação, investimentos, qualificação profissional, entre outros fatores, nas esferas pública e privada. E, essas características, fazem com que o estudo das instituições e serviços de saúde se tornem dificultosos, não obstante imprescindíveis. Nesse contexto, inclui-se além da necessidade de ampliar o conhecimento sobre suas particularidades, visando a melhoria contínua da atenção, entender os processos de trabalho que determinam questões pertinentes a saúde e o decorrente adoecimento dos trabalhadores, que efetivamente operacionalizam todo esse sistema. (Franco, Druck \& Seligmann-Silva, 2010). A partir desse pressuposto, as instituições de saúde precisam voltar a sua atenção, intenção e ações, para os trabalhadores que operacionalizam o cuidado, bem como para suas condições e processos de trabalho no campo da saúde. Nesse sentido, salienta-se que os referidos trabalhadores são, também, responsáveis pela qualificação da assistência e consequente potencialização dos resultados, almejada pelos gestores, mediante a implantação das políticas de qualidade (Pedroso \& Pilatti, 2010; Jorge, Carvalho \& Medeiros, 2013).

E, nessa busca pela excelência, vários são os programas versando sobre avaliação da qualidade na saúde, dentre eles, destaca-se a certificação para ‘Acreditação', oferecida pela Organização Nacional de Acreditação - ONA, desde 1999. É considerada a avaliação externa mais comum entre as instituições credenciadas no Brasil, alcançando 80\% desse mercado. Essa organização, por meio de suas instituições credenciadas, avalia hospitais, ambulatórios, laboratórios, serviços de pronto atendimento, home care; e serviços: oncológicos; de medicina hiperbárica; de hemoterapia; nefrologia e terapia renal substitutiva; diagnóstico por imagem; radioterapia e medicina nuclear; odontológicos; processamento de roupas para a saúde; dietoterapia; manipulação; esterilização e reprocessamento de materiais (Organização Nacional de Acreditação [ONA] 2020). De acordo com seus padrões pré-estabelecidos, a ONA tem o intuito de tornar seus acreditados em referências de assistência qualificada, mediante ambientes cooperativos organizados e profissionais comprometidos, e essas adequações favorecem a manutenção de uma equipe saudável e eficiente (Ditomassi, 2012; Jorge, Carvalho \& Sales, 2014).

Desse modo, faz-se necessário observar se as instituições que se preocupam com a qualificação dos serviços de saúde, públicas ou privadas, primam não somente pelo desenvolvimento de estratégias que possibilitem a melhoria contínua na assistência, na atenção ao usuário, no ambiente e nas condições de trabalho, mas sobretudo em processos de trabalho que viabilizem relações humanizadas inclusivas da subjetividade individual e coletiva dos trabalhadores, bem como sua saúde e bemestar. Desta forma, comtemplando inclusive a identificação dos riscos psicossociais ocupacionais, dos aspectos estressores do 
ambiente do trabalho e suas implicações sobre o estado de saúde geral do trabalhador: psíquico e fisiológico (Simões \& Hashimoto, 2013; Baruki, 2018).

Por conseguinte, nesse estudo, o foco da discussão está nas implicações de um conjunto de processos interligados da gestão, experienciados pelos trabalhadores de uma unidade de saúde municipal, no contexto do Sistema Único de Saúde - SUS, categorizada como unidade mista. A referida unidade é gerida, há 12 (doze) anos, por uma associação considerada de direito privado, natureza filantrópica, reconhecida de utilidade pública municipal, estadual e federal e qualificada como uma organização social (OS), contando com a participação de aproximadamente 294 trabalhadores.

Destacam-se, entre os fatores que corroboram para a análise desse estudo, a compreensão do modelo de gestão adotado, incluindo os elementos advindos do contrato de gestão (entre a Prefeitura Municipal - Secretaria de Saúde e a OS), contemplando cinco elementos: (1) o modelo de gestão do trabalho e a educação em saúde; (2) o cumprimento de metas; (3) o vínculo empregatício pela Consolidação das Leis Trabalhistas (CLT) ( Decreto-Lei nº 5452, 1943); (4) o ingresso de seus trabalhadores via processo seletivo público (desde sua fundação); e (5) o processo de certificação de acreditação da unidade, via metodologia da ONA (nível 1). Destarte, esse estudo tem por primícias conhecer as implicações da gestão do trabalho e do programa de qualidade sobre a saúde do trabalhador, intencionando ônus e bônus, sob a percepção dos trabalhadores e gestores, em uma unidade mista da rede SUS.

\section{Metodologia}

Trata-se de um estudo de abordagem qualitativa. Esse método, advém das Ciências Humanas e da Saúde, e tem como característica, não focar no fato, mas na sua significação coletiva ou individual, ou seja, o significado do objeto do estudo, extrapola o simples conhecimento do mesmo. A partir disso, o pesquisador precisa ter um olhar holístico e amplo para relacionar os fatos, as percepções e, apresentar um modelo novo, construído essencialmente a partir da visão e dos sentimentos dos participantes do estudo; sem, contudo, abrir mão do rigor científico que deve reger todos os métodos de pesquisa e as suas respectivas etapas. Neste método de pesquisa, o pesquisador se coloca no papel de mediador e não de detentor dos saberes assim os resultados são interpretados sob a ótica dos participantes com o objetivo de produzir novos conceitos e não simplesmente de confirmação de teorias pré-estabelecidas (Turato, 2005; Canzonieri, 2010).

A coleta de dados teve início, após aprovação do estudo pelo Comitê de Ética em Pesquisa com número do C.A.A.E: 06075019.7.0000.5152/ Número do Parecer: 3.221.277. Posteriormente a transcrição dos depoimentos, a identificação foi feita por meio de das letras "T" para os trabalhadores e "G" para gestores e códigos numéricos subsequentes para cada um, preservando assim a identidade dos participantes e da instituição, sem revelar qualquer informação relacionada a sua privacidade.

Incluiu-se no estudo, de forma intencional, 30 (trinta) trabalhadores de diferentes áreas da saúde (médicos, enfermeiros, cirurgiões-dentistas, assistentes sociais, farmacêuticos, nutricionistas e fisioterapeutas) e 8 (oito) gestores (municipais, da OS e da unidade de saúde do estudo), com funções e atribuições hierárquicas distintas, para garantir heterogeneidade da amostra (Cooper \& Schindler, 2003), permitindo avaliar a organização do trabalho e diferentes compreensões e óticas de implicações da acreditação. Para a coleta de dados optou-se pela utilização do Grupo Focal, técnica que permite compreender eventos que resultam das relações interpessoais, uma vez que participantes são impulsionados a problematizar questões críticas e tomarem decisão conjunta (Carline \& Contrim, 1996; Novaes, 2000; Tanaka \& Melo, 2004). Foram realizados dois Grupos Focais com quinze profissionais de saúde em cada um dos grupos. Os mediadores propuseram questões relacionadas com modelo de gestão por OS, gestão do trabalho, programa de qualidade (acreditação) interacionados entre si com as implicações na saúde do trabalhador. Adicionalmente, foram realizadas entrevistas semiestruturadas direcionadas a gestores, abordando os mesmos temas. Salienta-se que os profissionais de saúde que não puderam participar dos grupos focais, foram incluídos no estudo, por intermédio das referidas entrevistas. 
A interpretação dos dados, realizou-se a partir da técnica de análise temática de conteúdo, com base no modelo proposto por Bardin (2016), com adaptação de Minayo (2012). Essa interlocução entre os métodos das duas autoras buscou melhor compreensão do conteúdo e da mensagem dos discursos registrados, conferindo validade e credibilidade ao estudo, e promovendo, também, um aprofundamento na interpretação dos dados, a partir da inclusão de fatores históricos e contextuais, embasados na literatura nacional e internacional. Essa técnica é indicada como a forma mais adequada de estudar opiniões, valores, atitudes e crenças, com a utilização do método hermenêutico-dialético, para melhor compreensão das falas, em seu sentido e contextualização (Bardin, 2016; Minayo, 2012; Silva \& Fossá, 2015). Ademais, a inteiração com o método da Minayo (2012), na análise de dados, trouxe para além da compreensão da situação de saúde dos trabalhadores, uma abordagem sociológica, na interpretação e discussão dos resultados.

\section{Resultados e Discussão}

Os resultados obtidos ratificam os autores que recomendam grupo focal, anteriormente citados, considerando que a técnica grupal oportunizou, para além da disposição em verbalizar sentimentos e emoções, o compartilhamento de percepções frente a problemática em questão. Assim, motivados pelos depoimentos de seus pares, vários aspectos entre fatos, pormenores e particularidades, foram despertados, advindos de diferentes visões e entendimentos, que resultaram em reflexões e sentimento de pertencimento à um grupo, o qual experienciam ora as dificuldades cotidianas, ora as conquistas. Ademais, se reconheceram durante o compartilhamento dos desabafos relacionados ao esgotamento e adoecimento, decorrentes de suas atribuições laborais.

Construiu-se a análise de dados com o suporte da árvore de categorização do estudo (Quadro 1). Incluiu-se as principais categorias, que se formaram a partir dos depoimentos mais significativas e frequentes verbalizações dos trabalhadores e gestores, reunidos em cinco grandes temas da gestão da OS, fazendo um contraponto entre suas percepções.

Quadro 1 - Árvore de categorização do estudo, apresentando os principais temas e categorias abordadas, segundo os trabalhadores ou gestores.

\begin{tabular}{|c|c|c|}
\hline $\begin{array}{l}\text { TEMAS } \\
\text { (Geståo OS) }\end{array}$ & CATEGORLAS & PARTICIPANTES \\
\hline \multirow{2}{*}{$\begin{array}{l}\text { Tema } 1 \\
\text { Vinculo laboral celetista e } \\
\text { metas/lndicadores }\end{array}$} & $\begin{array}{l}\text { - Instabilidade pelo contrato via Consolidação das Leis do Trabalho } \\
\text { (CLT) } \\
\text { - Cobranças e exigéncias do contrato de gestão. }\end{array}$ & Trabalhadores \\
\hline & $\begin{array}{l}\text { - Caracteristicas do Contrato de Gestào e da Gestào da OS. } \\
\text { - Superioridade da gestĩo mediante OS. }\end{array}$ & Gestores \\
\hline \multirow[t]{2}{*}{$\begin{array}{l}\text { Tema } 2 \\
\text { Gestảo de Trabalhe e } \\
\text { ambiência }\end{array}$} & $\begin{array}{l}\text { - Politicas da gestão do trabalho. } \\
\text { - Precarização das condiçōes de trabalho. } \\
\text { - Meio ambiente de trabalho na OS. }\end{array}$ & Trabalhadores \\
\hline & - Caracteristicas e limitaçōes da gestăo do trabalho na OS. & Gestores \\
\hline \multirow{2}{*}{$\begin{array}{l}\text { Tema } 3 \\
\text { Educaçăo ua saude } \\
\text { (capacitaçăo profissional) }\end{array}$} & - Percepç̋̄es sobre a capacitação profissional na unidade do estudo. & Trabalhadores \\
\hline & - Diretrizes da capacitação profissional da OS. & Gestores \\
\hline \multirow{2}{*}{$\begin{array}{l}\text { Tema } 4 \\
\text { Saude do trabalhador/ } \\
\text { adoecimento fisico e meatal }\end{array}$} & 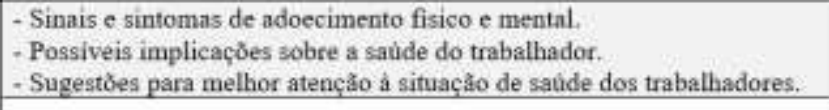 & Trabalhadores \\
\hline & $\begin{array}{l}\text { - Açóes e oportunidades de melhorias relacionadas na atençåo à saúde do } \\
\text { trabalhador. }\end{array}$ & Gestores \\
\hline \multirow{2}{*}{$\begin{array}{c}\text { Tema } 5 \\
\text { Acreditaçìo da qualidade ONA }\end{array}$} & $\begin{array}{l}\text { - Criticas ao processo de acreditaçáo na unidade. } \\
\text { - Potencialidades do processo de acreditação. } \\
\text { - Sugestoes de melhoria. } \\
\end{array}$ & Trabalhadores \\
\hline & $\begin{array}{l}\text { - Potencialidades da acreditaçåo. } \\
\text { - Percepçōes sobre a relaçî́o da acreditação e o trabalbador. }\end{array}$ & Gestores \\
\hline
\end{tabular}

Fonte: Autores. 
No Quadro 1, apesar das categorias estarem agrupadas didaticamente em temas distintos, não são achados isolados, ao contrário elas se interacionam, durante todo o percurso dos grupos focais e das entrevistas, em movimentos ora concordantes, ora antagônicos. E, foram assim construídas, no intuito de apresentar as similaridades e as contraposições dos depoimentos dos participantes, bem como demonstrar a relevância dos debates propostos pelo estudo. A partir dessa categorização, apresenta-se a transcrição ipsis litteris dos depoimentos sistematizados de trabalhadores e gestores, mediante análise de conteúdo temática.

\section{Tema 1 - Gestão OS: vínculo laboral celetista e metas/indicadores}

A unidade de saúde em estudo, é gerida por OS, desde sua abertura, por consequência todos são contratados pelo vínculo laboral celetista (CLT). Isto posto, observou-se que os depoimentos dos trabalhadores convergiram para três elementos: ausência de estabilidade no emprego, as exigências constantes e o cumprimento de metas e indicadores.

"[...] Eles ficam de olho. Tem a cobrança, não só por parte deles, mas da prefeitura também. Eles têm acesso a quantos atendimentos a gente tem. Tem, tem meta sim. Eu já vi gente que não atendia muito [...] aí foi demitido. " (T10)

"E então se eu não fizer meu trabalho, tem outra melhor que vai fazer [...]. E coloca outra pessoa no lugar. É isso que acontece. E eu morro de medo porque eu tenho minhas contas, mas manda quem pode e obedece quem tem conta para pagar [...]" (T21)

"[...] Todo mundo está no mesmo barco, ninguém tem privilégios, todo mundo está nessa pressão desses protocolos, desses resultados, de vez em quando você vê um com a saúde mental piorando. Chora, sai correndo. Mas você vê como está a situação lá fora. Aí pensa... O emprego não está muito fácil... Começar numa casa nova vai chegar também os protocolos... Então um vai apoiando o outro e vai levando... " (T5)

Em contraponto, os gestores demonstram racionalização no processo de exigências, pois é condicionado ao cumprimento das mesmas, o repasse integral dos recursos financeiros. Em adição, destacam a superioridade da gestão OS, devido às vantagens financeiras para o município, nos quesitos de flexibilização, transparência e agilidade nas licitações.

"Vejamos, é uma organização privada, certo? Sem fins lucrativos. Então, ela também tem uma vertente, que é muito interessante, isso gera benefício ao município. Com a questão da cota patronal, ela já tem um negócio 25\% mais barato que qualquer empresa [...]. Você ter uma condição que flexibiliza para eles as contratações [...]. Ela desonera a folha de pagamento e tudo mais. E além disso, ela propicia, através da OS, uma flexibilidade, uma maior agilidade daquilo que são as licitações." (G4)

"[...] Todo mês tem prestação de contas, a OS tem que atingir as metas, se não atinge as metas, ela vai receber um recurso menor, e isso é ruim [...], porque é dinheiro a menos [...]. A prestação de contas ela é aberta, é pública, quando há divergências, o ministério público entra como mediador." (G1)

Em suma, evidenciou-se, na percepção dos trabalhadores, que a gestão por OS traz incertezas em relação à permanência no vínculo laboral, agravados pelo monitoramento do cumprimento de metas e indicadores, desdobra-se em um profissional cotidianamente pressionado e temendo substituição repentina (Fernandes, Soares, Turino, Bussinguer \& Sodré, 2018). Em contrapartida, gestores consideram natural e recomendável as exigências de produtividade, reconhecendo a parceria públicoprivada, lucrativa para gestão municipal e favorável na atenção à saúde da população. Isso demonstra que os gestores trabalham 
absortos, no sentido de imersos em entendimentos circunscritos a visão gerencial e o benefício comunitário e, por vezes, indiferentes ao experienciando pelo trabalhador, focados nas pressões que sofrem em suas funções e desatentos, alheios e descuidados com o cuidador - trabalhador da saúde (Gaulejac, 2007).

A realidade da precarização do trabalho, no contexto neoliberal, advém da priorização do lucro e do aumento da produtividade, que resultam em ambientes de trabalho competitivos, nos quais os trabalhadores se sentem permanentemente temerosos e inseguros, quanto à estabilidade de seus empregos. Essa realidade traz um desiquilíbrio nas relações de trabalho verticais que potencializam o desgaste laboral físico e emocional, que perpassam pela quebra da confiança e cooperação, entre os colegas de labor, e pela sobrecarga de atribuições e cobranças, advindas de gestores, que na busca da excelência das suas empresas, sacrificam o bem-estar e a saúde de seus trabalhadores (Seligmann, 2016).

Ademais, a instabilidade do vínculo celetista, atado à exigência do cumprimento de metas gera um receio de desligamento da instituição. De fato, o Conselho Nacional de Secretários de Saúde (CONASS) traz que essa é a realidade do sistema de saúde brasileiro, a partir da terceirização, na qual se introduziu distintos vínculos empregatícios, nem sempre protetivos do trabalhador (Conselho Nacional dos Secretários de Saúde [CONASS], 2011). E essa diversidade de vínculos resultou em 'gestão do trabalho' mais complexa e desafiadora, pois altera-se não só a forma de ingresso no serviço público, mas também o tempo de permanência, uma vez que esses trabalhadores não gozam de estabilidade garantida aos servidores públicos (Costa E Silva, Barbosa \& Hortale, 2016).

Nesse contexto, os gestores têm maior liberdade na gestão dos trabalhadores, resultando por um lado em maior autonomia, flexibilidade e agilidade para resolução de aspectos cotidianos do trabalho, porém, ao mesmo tempo, gera medo e instabilidade para os trabalhadores por se sentirem pressionados e receosos de perderem seus empregos (Cooper, 2005). Nessa conjuntura, de transformação das relações de trabalho, urge a necessidade de criar espaços de debates com participação legitima do trabalhador que permitam estabelecer um equilíbrio entre as exigências dos gestores e as reinvindicações dos trabalhadores (CONASS, 2011; Pacheco, Júnior, Santos, Ferreira \& Leal, 2016).

\section{Tema 2 - Gestão OS: Gestão do Trabalho e ambiência}

Em relação à política de gestão do trabalho, os trabalhadores citam que possuem os seguintes benefícios: redução de mensalidades para estudo em instituições de ensino superior, liberação para participação em um congresso anual (restrito a médicos e dentistas), vale alimentação e folga de aniversário. Entretanto, os trabalhadores reivindicam revisão das condições para receber tal "benefício", pois tanto a folga de aniversário e o vale alimentação estão condicionados a ausência de atestados por afastamento médico desses trabalhadores.

"[...] Os benefícios são o vale alimentação. A folga de aniversário, sempre incentivando que se caso pegar atestado mais que 3 dias, vai perder o vale alimentação [...]. A folga de aniversário é agendada, tem que ser um até um mês depois, do seu aniversário. Às vezes a gentes escolhe, as vezes o dia pode não dar certo, mas é negociável." (T11)

"A instituição, como qualquer outra instituição, dá aquele desconto [...] em uma faculdade, numa pós. Nesses casos tenta negociar com a coordenação [...] (T13)

"Uma vez por ano, a gente tem direito a 1 Congresso, só que tipo, 30 dias antes eu apresento, onde vai ser, apresento a inscrição. (T5)

As pré-condições para recebimento do vale-alimentação e da folga de aniversário acabam por corroborar para o que denominamos como presenteísmo, no qual os trabalhadores, mesmo doentes, escondem sua condição e permanecem 
desenvolvendo suas atividades, ou por receio de demonstrarem suas fraquezas e perderem seus status de funcionários saudáveis e produtivos (Seligmann, 2016), ou ainda por perderem benefícios, como relatado pelos participantes do estudo, que muitas vezes preferem negociar folgas ou invés de apresentarem atestados.

Entretanto, o presenteísmo, a médio prazo pode causar a perda de produtividade do trabalhador, pois o agravamento de sua condição de saúde o torna incapaz, mesmo que temporariamente, de realizar suas atividades de forma eficaz, e a longo prazo, a impossibilidade de permanecer no trabalho, gera afastamentos prolongados, "maiores custos previdenciários e de tratamento" (Seligmann, 2016, p. 191)

As condições de trabalho na unidade também foram mencionadas, de forma recorrente, incluindo fragilidades estruturais (físicas), do abastecimento de medicamentos, assim como das condições dos equipamentos e dos computadores que são insuficientes para todos os profissionais, além de obsoletos.

"A estrutura física, a gente percebe que está passando por reformas agora, a gente não é totalmente preparado para internação [...]. Então a gente dispõe de poucos leitos de cama. E, a gente vai improvisando com as macas, para tentar atender, o mínimo de conforto do paciente, mas infelizmente essa parte é um pouco falha." (T14)

"Os computadores têm que melhorar, porque eles travam muito, o sistema cai bastante [...]. O tamanho da sala é bom, as coisas que a gente precisa no geral são boas. É de vez em quando falta um medicamento que a gente precisa [...]. " (T9)

Nesse aspecto, a melhoria das condições do ambiente de trabalho é de responsabilidade dos gestores, e essas adequações são necessárias para diminuir os fatores extrínsecos que podem ser considerados estressores na rotina dos trabalhadores e geradores de absenteísmo por afastamentos médicos, ou mesmo, do presenteísmo que impacta no desempenho dos profissionais. Tudo isso é prejudicial para a instituição e poderia ser evitado mediante um monitoramento periódico e cuidadoso frente a condição de saúde dos trabalhadores e a promoção de práticas e ações que possam evitar o adoecimento dos mesmos (Kilimnik, Bicalho, Oliveira \& Mucci, 2012; Potocka, 2012).

Os trabalhadores ainda reivindicam a adoção pela gestão OS, de outros benefícios ou estratégias que possam motiválos no trabalho, considerando a insuficiência de ações que valorizem os mesmos.

"Então, pode ter incentivo de várias formas. Às vezes, melhoraria a motivação de trabalhar. O psicológico também. É melhor do que depender de medicação, porque hoje nós somos cobrados, até crianças tem problemas com ansiedade. Isso só está aumentando." (T1)

Salienta-se, reflexões afirmativas sobre a ambiência e as relações interpessoais entre os trabalhadores. Há unanimidade de elogios entre os profissionais e equipes de trabalho, fortalecendo o companheirismo, compartilhamentos e união entre pares, para alcançar os objetivos dessa unidade de saúde.

"A gente tem uma equipe muito unida, muito comprometida, muito comprometida mesmo, então assim, por isso que as coisas caminham, entendeu? Tem a questão da união e de comprometimento, porque se a gente tivesse uma equipe desunida, que não tivesse unida no mesmo propósito, com certeza não tínhamos chegado aonde à unidade chegou." (T29) 
Diante da escassez de mecanismos de suporte e canalização do estresse, os trabalhadores buscam na cooperação coletiva a força necessária para suportarem as condições adversas do trabalho (Dejours, 2012), nesse sentido as relações interpessoais precisam estar baseadas na confiança e acontecerem de forma natural, ou seja, sem imposições gerenciais, para que resultem em um movimento unidirecional objetivando o bem comum e a solidificação de um campo de trabalho agregador e saudável (Macêdo, Fleury, Bueno \& Pires, 2013; Carneiro \& Silva \& Campos, 2018).

Ainda nesse sentido, os trabalhadores tendem a desenvolverem estratégias coletivas de defesa, que se tornam mecanismos de cooperação e coesão no ambiente de trabalho, como forma de enfrentamento da pressão e do sofrimento decorrentes da rotina laboral, no intuito de ressignificar o trabalho diário em resistência e vivência não só individuais, mas também coletivas (Dejours, 2007).

A visão dos gestores se aproxima da ótica dos trabalhadores, ao reconhecerem suas limitações, diante das necessárias alterações no 'contrato de gestão', referente a ampliação de benefícios e incentivos financeiros. Entretanto, se afirmam conscientes e sensíveis a premência em buscar estratégias de valorização dos trabalhadores.

"Na realidade, a gente trabalha e tem trabalhado todos os dias, com os talentos humanos, esse departamento, também é uma questão diferente do poder público, porque a gente pelo contrato, força do contrato, a gente não pode ter plano de cargos e salários [...] que seria o ideal, mas o que a gente consegue, às vezes, dentro do nosso escopo de trabalho é promover alguém aqui dentro, ou em relação a alguma bonificação de algum trabalho extra que ele faz [...]. (G5)

"A gente é limitado, como eu disse, o que a gente consegue, por exemplo, é uma parceria com instituições de ensino, como descontos, com bolsas, né [...], mas a gente busca, lógico, sempre dentro da carga horário dele, se ele consegue conciliar, né? [...] Em acordos com instituições de ensino, e treinamento também [...]” (G5)

Desse modo, faz-se necessário, a busca e a implementação de outras formas de valorização profissional, inclusivos de mudanças nas estratégias e políticas da gestão do trabalho, que envolvem a qualificação profissional, atividades motivacionais e o desenvolvimento de competências que promovam segurança e autonomia profissional (Hung, 2013; Pacheco et al., 2016; Paraízo \& Bégin, 2020). Nesse contexto, a implementação de estratégias similares ao Plano de Cargos, Carreiras e Salários PCCS e o incentivo à qualificação dos trabalhadores da saúde e de suas equipes faz com que os mesmos se sintam valorizados e mais seguros para realizarem procedimentos clínicos básicos e especializados, conforme sua formação profissional (Santos \& Lacaz, 2013).

\section{Tema 3 - Gestão OS: Educação na saúde (capacitação profissional)}

No âmbito da gestão municipal, os trabalhadores consideram as estratégias das educações, permanente e continuada, ainda incipientes e fragmentadas, com iniciativas isoladas e ausência de programas consolidados. Refletem que na unidade de saúde, também, ocorre essa fragmentação, pois as capacitações oferecidas, geralmente, não se iniciam por meio de planejamento estratégico e não seguem um plano de continuidade, sendo realizadas mediante as demandas mais urgentes, tais como os treinamentos para implementação de programas, protocolos ou alterações nesses últimos.

"Não tem assim, uma educação continuada para chamar todo mundo. Tem assim pequenos focos de educação só."

"É esporádica, a gente tem alguns protocolos que quando são instituídos a gente até é capacitado para isso, mas assim, nada contínuo não. Uma capacitação com plano de educação continuada. Não tem não. É esporádico." (T7) 
"Não tem a educação continuada aqui, é em relação à demanda, a gente está com dificuldade em alguma coisa, a gente está com uma demanda [...]Então eu vou pegar a equipe e treinar específico naquilo. Depois que eu já tenho um problema especifico [...]" (T16)

Observou-se também que os gestores se mostram receptivos frente a necessidade de melhoria nessa área, sugerindo implementação de programas continuados de formação de líderes e treinamentos da equipe.

"[...] A gente trabalha com a capacitação de lideranças, né. Porque a gente tem equipes sendo geridas por gestores que precisam também desse subsídio e desse apoio, desse suporte, então a gente oferece." (G5)

"Hoje a gente percebe que quer trabalhar com qualidade, a gente vai começando a ver que para os processos funcionarem, você tem que ter treinamento na equipe. Então a gente vai, organiza com o corpo que a gente tem mesmo, e faz [...]. Mas isso é feito permanente..." (G8)

Os trabalhadores da unidade são motivados a participarem de cursos, congressos e atualizações, entretanto, desde que haja reposição dessa carga horária, essa antítese, restringe e dificulta a adesão às capacitações externas. Os gestores consideram as horas em capacitação geradores de absenteísmos, uma vez que comprometem a meta e decorre em descumprimento da carga horária prevista no seu contrato de trabalho, e por isso se dizem 'impossibilitados', por força do 'contrato de gestão' e da legislação trabalhista, de liberarem seus trabalhadores. Desta forma, é recomendado ao trabalhador a negociação, junto ao coordenador, para posterior reposição no trabalho, das correspondentes ‘horas perdidas em capacitação' ou a participação dos cursos externos extra horário de seu trabalho.

"Juridicamente a gente não pode, infelizmente ir liberando, as pessoas, para fazerem determinados tipos de ações, porque como a gente é engessado em metas, a gente faz uma contratação que é por CLT, que tem uma carga de trabalho, então a gente sabe que um curso externo, alguma coisa fora, a gente vai alterar a carga horário de trabalho do trabalhador, e como a gente presta conta em relação àquela carga horária e a meta que ele tem que cumprir, isso fica um pouco dificil.", (G5)

No contexto da educação na saúde, nas duas modalidades: educação continuada e permanente no Brasil, verifica-se desconhecimento ou não seguimento, no âmbito de execução das políticas e da gestão de educação na saúde, advindas da Política Nacional de Educação Permanente em Saúde (PNEPS), instituída em 2004. É raro, também, sobrevir manutenção de estratégias continuadas de educação na saúde, tanto no âmbito local, quanto no campo das macropolíticas de estado, devido a entraves financeiros, políticos e gerenciais (CONASS, 2011).

Assim, apesar dos avanços, observa-se no país, momentos isolados de educação 'não-continuada', junto a práticas insuficientes para capacitarem os trabalhadores, pois não lhes fornece conhecimentos adequados e suficientes, para completarem de forma satisfatória o processo de ensino-aprendizagem, essenciais para a qualificação e atualização das práticas clínicas e de saúde coletiva. E torna-se agravante nesse contexto, a escassez de oferta de cursos de atualização e especialização, advindas da gestão, nas três esferas de governo, associada aos entraves relacionados com a liberação dos mesmos para participarem integralmente dessas atividades de educação continuada (CONASS, 2011; Peres, Silva \& Barba, 2016). 
Destarte, a política oficial de educação permanente em saúde traz em seu bojo a exigência ético-política de um processo educativo incorporado ao cotidiano da produção setorial (no trabalho), que apesar de ser um desafio ambicioso, faz-se necessário (Portaria nº 198 GM/MS, 2004; Ceccim, 2005).

\section{Tema 4 - Gestão OS: Saúde do trabalhador/adoecimento físico e mental}

Os depoimentos revelaram sinais e sintomas de adoecimento dos profissionais da saúde, corroborados pela precarização de certas condições de trabalho, aumento da demanda assistencial, acúmulo de atribuições e exigências do cumprimento de metas/indicadores. É perceptível aos trabalhadores a relação entre a vivência de fatores afetos a sua rotina de trabalho, atuando como 'potencializadores' de problemas de saúde pré-existentes e ocupacionais (ansiedade, estresse, enxaquecas, etc.) ou desencadeadores de adoecimentos físico e/ou mental. Reconhecem a resiliência e a resistência como atitudes essenciais para o enfrentamento dos desafios diários do trabalho.

"A rotina do dia-a-dia, acaba gerando esse estado de estresse, de ansiedade [...] então a cobrança tanto do paciente que quer receber um tratamento de qualidade em todas as áreas, quanto da coordenação, por exemplo, e da secretaria de saúde, que quer exigir meta [...] a gente se sente pressionado, isso é evidente, gera uma situação de ansiedade, estresse. E tem que ter um controle muito bom, ao longo do ano, do mês, para poder suportar tudo isso." (T30)

"Eu também tenho enxaqueca muito forte, muito forte. Chegou alguns momentos que eu achei que estava com algum tipo de tumor no cérebro [...] aí, eu entrei de férias, foi como se eu nunca tivesse sentido dor de cabeça na vida. No primeiro dia que eu volto, a dor de cabeça volta." (T26)

Os trabalhadores relatam as possíveis causas desse adoecimento, descrevendo em seus depoimentos os principais fatores externos e internos ligados diretamente e indiretamente à assistência ao paciente e às atribuições diárias próprias de suas categorias profissionais.

"Eu acho que a gente tem ficado muito exposto, a população não tem compreendido. E como tem sobrecarregado, $e$ ficado bem cheio o pronto socorro, eles têm ficado muito nervosos, e ficado agressivos com a gente [...]" (T9)

"Eu acho mais difícil a parte das pessoas, de número de pessoas, do que em relação a insumos. Os insumos a gente acaba se virando mesmo, se organizando, improvisando, mas agora a parte de pessoal realmente a gente chegou no limite." (T16)

Ainda nesse quesito, os trabalhadores listaram sugestões para minimizar o impacto dessa realidade tanto no ambiente profissional quanto em sua vida privada.

" Faz falta de a gente ter um momento no plantão de relaxar sabe? [...]A gente tinha uma equipe que chegava lá e falava assim [...] agora a gente vai fazer alongamento. E ficava 10 minutos com a gente, ficava 10 minutos com a gente assim. E era uma coisa maravilhosa, você parece que saia tão bem [...]” (T14)

"E eu vejo assim, [...] mesmo que seja para desabafar, a gente não tem a quem acessar com relação a isso. Um psicólogo, uma equipe de apoio com relação a doença ocupacional mesmo, assim, para aliviar mesmo o estresse [...]E infelizmente, eu fui umas das pessoas que fui parar no psiquiatra e que faço uso de medicações." (T16) 
"Eu faço academia, $3 x$ na semana. E a gente dá plantão também no final de semana, mas eu consigo conciliar o momento que eu estou de folga, eu desligo mesmo. Vou curtir minha família, curtir minha filha, tranquilo." (T18)

Em contrapartida, a percepção dos gestores, sobre a saúde de seus trabalhadores, refere-se à implementação de ações direcionadas para segurança ocupacional. Apesar de demonstrarem relativa abertura e cônscios da necessidade de uma maior atenção nessa área, bem como da indispensável implementação de ações para proteção da saúde física e emocional de seus profissionais. Revelam ainda, que existem projetos em desenvolvimento e reconhecem a importância do monitoramento, da condição de saúde dos trabalhadores da unidade, inclusive para determinarem se existe ou não um nexo causal entre a o adoecimento e o trabalho, como por exemplo, na Síndrome de Burnout. À primeira vista, a gestão intenciona desqualificar a relação entre o trabalho e saúde e, desta forma, incomoda e preocupa-se com o nexo causal.

"No meи entendimento como gestor, eи penso que a gente sempre deveria estar fazendo mais [...] Eu gostaria que tivéssemos outros momentos, de outras oportunidades de estar fazendo mais pelo nosso colaborador, porque é bem estressante [...]" (G5)

"O que eu vejo de ações efetivas do SESMT, [...] a gente trabalha mesmo é a questão de cuidados, de equipamentos de proteção individual [...]. É um ponto, talvez de fragilidade da instituição, que precisa ser melhorado. Com certeza." (G7)

"Na saúde, existem os riscos, existe problemas porque é insalubre [...]. Agora, uma questão, já que o pensamento é sobre o trabalho, o que precisa ver, é a pessoa integral., porque as vezes trata como uma pessoa que está com Síndrome de Burnout, que ela adquiriu isso no ambiente de trabalho [...](G3)

"Mas a instituição, com certeza precisa melhorar e muito na abordagem tanto nas questões de condição de ambiência, quanto no aspecto de suporte emocional para esse profissional que está ali na ponta, na assistência. Porque aquilo ali é uma guerra [...] Com certeza, é uma fragilidade, e a gente tem que assumir e encarar, e precisamos ver como nós vamos melhorar isso." (G7)

Os trabalhadores quando adoecidos apresentam perda de produtividade e queda no desempenho, acarretando prejuízos financeiros, também, para a organização social, na medida que aumenta a rotatividade de trabalhadores e acarreta em perdas operacionais pela ausência e/ou substituição desses profissionais (Paiva, Gomes \& Helal, 2015; Sobral, Stephan, Bedin-Zanatta \& De-Lucca, 2018). Desta forma, foi possível perceber que os gestores são capturados pelo seu papel de "gestor", onde o principal interesse é a administração e organização de processos, postergando os anseios e interesses dos trabalhadores.

O dia-a-dia dos trabalhadores da saúde é por si só desgastante, porque eles lidam não só com a vida, mas também com o risco de morte, a dor e o sofrimento de seus pacientes. Outrossim, pode comumente potencializar-se por conflitos interpessoais e familiares, que trazem um desiquilíbrio para o profissional. Esses fatores mencionados, associados ao aumento da demanda e ao subdimensionamento das equipes, geram implicações não só físicas, mas também emocionais e afetivas para seu cotidiano. Isto posto, torna-se importante a criação e implementações de estratégias gerenciais que busquem minimizar os efeitos deletérios dessas realidades, pois as condições de vida e trabalho desses profissionais impactam também na qualidade do serviço que ele oferece (Boldor, Bar-Dayan, Rosembloom, Sherme \& Bar-Dayan, 2012; Ferreira, Neto, Kilimnik \& Santos, 2016).

E esses fatores associados podem manifestar junto aos trabalhadores sinais e sintomas da Síndrome de Burnout, conhecida também como a Síndrome do Esgotamento Profissional, na qual o trabalhador se encontra em um estado de extrema 
exaustão física e emocional, ocasionada pelo excesso de cobranças por maior produtividade e alcance de metas, pelos conflitos interpessoais no ambiente de trabalho e também pela sensação constante de fracasso diante da pressão por ser e fazer o melhor sempre. Essa síndrome é de difícil diagnóstico e tratamento, entretanto ela é possivelmente evitada mediante a implementação de estratégias individuais, coletivas e organizacionais, relacionadas com a promoção de saúde no ambiente laboral, que pressupõe a identificação dos fatores estressores e o desenvolvimento de ações efetivas para minimizá-los na iminência de não mais causarem adoecimento dos trabalhadores (Mendanh, Bernardes \& Shiozawa, 2018).

A partir dessa constatação, o trabalhador se vê num lugar de luta diária contra o sofrimento e angústia de permanecer no labor, quando quer fugir, e isso representa o start para o adoecimento não só físico, mas também psíquico (Dejours 2012). Destarte, sugere-se a construção de espaços laborais abertos à negociação e ao debate que são capazes de gerar mudanças significativas nessa realidade deletéria, resgatando o sentimento de pertença e felicidade relacionados com o ambiente de trabalho e suas atribuições (Carneiro, Silva \& Ramos, 2018).

Nessa perspectiva, amplia-se as discussões sobre produtividade, desempenho, remuneração, benefícios e qualidade na assistência, entretanto não se pode descuidar do fator humano do setor da saúde, na valorização das pessoas que executam e recebem as ações e que, portanto, não se pode limitar ao desenvolvimento técnico ou à exigência dos contratos pré-estabelecidos, pois todas essas mudanças e/ou exigências impactam também na vida e na saúde dos trabalhadores (CONASS, 2011).

Há que se desenvolver uma expertise gerencial que consiga equilibrar a visão coorporativa e a identificação profissional para que os trabalhadores imersos em cobranças e exigências consigam reencontrar o verdadeiro sentido do trabalho, e que esse não seja exclusivamente um local de exigências e desgastes, mas também de crescimento e prazer (Gaulejac, 2007). No qual os trabalhadores sejam impulsionados a se movimentarem coletivamente de forma participativa e cooperativa, sendo livres também para imprimirem sua identidade, expondo suas opiniões e confiantes para exercitarem sua criatividade no ambiente corporativo (Dejours, 2012). Essa troca horizontal de saberes, associada a valorização subjetiva do trabalhador corroboram para a construção de um ambiente de trabalho saudável e equilibrado, no qual o sofrimento psíquico não se sobrepõe à alegria e satisfação diárias (Carneiro, Silva \& Ramos, 2018).

\section{Tema 5 - Gestão OS: Acreditação da qualidade ONA}

A percepção hegemônica dos trabalhadores é que a ‘Acreditação’ é benéfica para si e para os usuários. Em paradoxo, essa constatação vem acompanhada pelo reconhecimento de que os padrões de qualidade podem trazer uma sobrecarga de atribuições, exigências e, também, um distanciamento do paciente, exigindo ajustes nos processos de trabalho. Sugerem priorizar, durante o atendimento do usuário o acolhimento, e a atenção 'frente a frente'/ 'olho no olho' em detrimento de inúmeros registros formais, concentrando o profissional na digitalização dos dados do paciente no computador, exigidos pela metodologia de avaliação/acreditação da qualidade ONA.

Segundo suas percepções, as principais fragilidades da implementação da acreditação são: burocratização do trabalho; falta de gerenciamento dos protocolos; subdimensionamento de profissionais em algumas áreas, especialmente, dos técnicos de enfermagem; e a ausência da 'cultura da qualidade', ainda em construção. Quando das visitas dos avaliadores da acreditação, os trabalhadores se sentem sobrecarregados pelos ajustes que precisam ser desempenhados/elaborados, em curto período de tempo. E, desta forma, todos esses fatores geram estresse, principalmente pela cascata de exigências que recaem sobre o trabalhador.

"Também concordo que sobrecarrega um pouco porque o excesso de protocolo, o excesso de diretriz, às vezes, te deixa um pouco mais preso, no que você vai fazer, em relação ao atendimento, a gente acaba tendo menos tempo com o paciente, e mais tempo com o protocolo, quando você acaba o atendimento, você vai preencher papel". (T30) 
"Eu acho que ainda não temos uma cultura de qualidade. A gente tem uma cultura de visita... [...]. Tem visita, todo mundo surta, e trabalha um mês [...] e isso acaba gerando um descrédito com relação ao processo de qualidade. E fica assim tapando o sol com a peneira, maquiando para visita. Infelizmente." (T16)

Entretanto, mesmo com as dificuldades, existe um consenso a respeito da relevância da implementação da acreditação, e que o referido programa de qualidade, traz padronização dos protocolos e atendimentos, além da organização dos processos de trabalho, contribui para a melhoria contínua da assistência ao paciente e de sua segurança. E, traz respaldo ao profissional, mediante o registro seguro nos prontuários e planilhas de apoio.

"Cada setor tem um volume de protocolos de tudo que é feito dentro daquele setor, e aí tem um protocolo geral da OS, então eu acho que é uma maneira ideal de organizar, de organização que deixa bem à frente das outras unidades e vem crescendo, isso vem crescendo ao longo dos anos, de alguns anos para cá, tem ficado cada vez mais à frente o desenvolvimento de um atendimento de qualidade." (T30)

"Eu só vejo pontos positivos. A Acreditação faz a gente trabalhar mais em cima de protocolos, faz a gente promover mais protocolos, quando eles vêm aqui na unidade, eles enxergam coisa que a gente já está engessado e não está vendo mais, então eu só vejo que teve melhoria para o paciente, para o respaldo do nosso trabalho [...]” (T11)

Os trabalhadores sugerem melhorias, dentre elas, a criação de um 'plano de ações continuadas', intentando preparar os profissionais para seu desempenho nos processos da acreditação, quando das visitas dos avaliadores. Relatam a necessidade de uma revisão dos protocolos visando sua otimização e reduzi-los no quesito quantidade.

"[...] É estressante porque tem muitos protocolos que tem que seguir, tem 'n' coisas, tem que preencher muito papel, quando tem a visita dos avaliadores tem que acompanhar. Então assim, é muito desgastante, mas, é bem positivo para o paciente. É, o que você não pode fazer é deixar a casa arrumada, só quando vai receber visita. Tem que ser todo dia." (T15)

Similarmente, os gestores evidenciam percepção positiva em relação à implementação da 'Acreditação' da qualidade ONA, decorrente, em seu primeiro momento, de exigência do 'contrato de gestão', todavia, atualmente, transcendeu-se, sendo bem aceito e consolidado na unidade de saúde, evidenciado pelos bons resultados e benefícios, aos usuários e trabalhadores, especialmente, nos quesitos segurança e qualidade da assistência.

"Na assistência tem muita diferença nos processos de trabalho [....] Na assistência a gente vê muito isso. Até o próprio paciente, o colaborador da ponta, ele vê diferença [...]" (G8)

"Em uma unidade acreditada a exigência é maior, tanto de quem está trabalhando, como de quem busca o atendimento [...] você exige mais daquela unidade. E não quer dizer que você, por ter qualidade, você não tem erros, ou falhas no processo. Pelo contrário, quando você institui um processo de qualidade você consegue enxergar melhor e entender que aquilo que está sendo feito, talvez não seja da melhor forma, você então faz todas as adequações necessárias, as implantações necessárias." (G2) 
Entretanto, quando o assunto são as implicações na saúde do trabalhador, os gestores, em sua maioria, discordam que os padrões de qualidade da acreditação possam trazer sobrecarga de atribuições ou mesmo estresse. Paradoxalmente, concordam que as exigências aos trabalhadores são maiores, em unidades acreditadas, quando comparadas as unidades de gestão convencional.

"A qualidade não é um fator a mais de estresse, pelo o que estou vendo em termos de protocolos, em termos do dia-adia [...]então, pode até gerar um estresse, um cansaço, talvez, qualquer coisa para quem não está a fim é estressante, né?" (G6)

“[...] O registro em si é parte da atividade. É parte da função. Então inserir planilhas, retirar planilhas, digitar isso, digitar aquilo. Não necessariamente acarreta uma carga de trabalho, uma carga excessiva, que vai causar estresse. Não em todas as situações, cada caso é um caso." (G6)

"[...] É, logicamente que a cobrança do trabalho, ela aumenta, porque a exigência é aumentada, os critérios de acompanhamento, mas isso eu vejo como algo importante para empresa e mais importante é para o colaborador que participa de um processo de qualidade, entendendo até como algo diferencial no seu currículo, de ter um olhar diferenciado no porquê que eu estou fazendo aquilo." (G2)

Observou-se alinhamento de percepções, de trabalhadores e gestores, quanto aos inúmeros benefícios da acreditação da qualidade ONA, tais como: respaldo profissional mediante os protocolos clínicos validados e organização da unidade e dos fluxos de atendimento. Cabe ainda ressaltar, que o processo de acreditação produz também orgulho nos trabalhadores, pois se sentem valorizados quando recebem uma avaliação positiva, tanto relacionado aos processos e protocolos, quando à organização estrutural estabelecida (Manzo, Brito \& Corrêa, 2012).

Entretanto, quando se fala do aumento das exigências e cobranças da acreditação, os trabalhadores se mostraram críticos devido à sobrecarrega dos profissionais da assistência e subdimensionamento de trabalhadores. Sabe-se que um dos fatores causadores de estresse do trabalhador, está relacionado as condições de trabalho, tais como a escassez de insumos e recursos humanos. Entretanto, em unidades acreditadas, esperava-se que esses problemas fossem minimizados, mesmo no âmbito da saúde pública. Desta forma, faz-se necessário identificar os principais pontos críticos, e se necessário reorganizar os processos de trabalho ou ainda redimensionar o número de profissionais, para diminuir a pressão sobre os mesmos (Higashi, Simonetti, Carvalhaes, Spiri \& Parada, 2013; Panizzon, Luz \& Fensterseifer, 2008).

Além disso, existe uma contraposição nos pressupostos de implantação do processo de acreditação, que precisa ser ajustada, pois ela deveria promover o bom relacionamento da equipe com os pacientes, e isso pressupõe momentos de escuta e de diálogo, que não poderiam ser suplantados pelo tempo de preenchimento do prontuário. Assim, a qualidade na assistência não pode estar ligada somente às adequações técnicas, ela envolve as dimensões interpessoais e ambientais, que geram mudanças tanto na relação trabalhador/paciente, no sentido da humanização dos cuidados, quanto no ambiente físico, para que o tempo do paciente nessa unidade, se torne confortável e agradável (Mezomo, 2001; Lima \& Edermann, 2006).

Os gestores consideram que quando se acordam metas e demais processos da acreditação, as mesmas são inerentes as atribuições dos trabalhadores, e por isso não geram estresse e nem adoecimento e depende, exclusivamente, do comprometimento e da responsabilidade desses trabalhadores. Entretanto, dentre as principais causas do adoecimento dos profissionais da saúde está a sua rotina de trabalho estressante, exigente de atenção permanente para uma correta tomada de decisão. Assim, as exigências (cobranças), o aumento da demanda e a escassez de profissionais são alguns dos determinantes no desequilíbrio saúdedoença dos trabalhadores (Andrade, Albuquerque \& Andrade, 2011; Abini, Zoni, Parrinello, Benedetti \& Lucchini, 2011). Em 
decorrência, se faz necessária uma maior atenção dos gestores na introdução de políticas preventivas de doenças e agravos, bem como de proteção e apoio aos trabalhadores, incluindo a avaliação do clima organizacional e das condições de trabalho. Indicase a gestão do trabalho construída de forma participativa, tornando-se mais equilibrada e justa, também na visão do trabalhador (Ferreira et al., 2016).

Nessa perspectiva, insere-se aqui uma crítica sobre a priorização do desempenho, da produtividade, mediante padrões pré-estabelecidos, em detrimento da pessoa executante dessas ações. Por muitas vezes, o trabalhador é visto somente como mais um dos fatores a ser moldado ou colocado na fôrma. Implantam-se modelos de gestão com padrões de medidas de qualidade a serem seguidos, mas, em contrapartida, não são mensurados os danos que o aumento da pressão pode causar na vida e na saúde dos trabalhadores, tanto daqueles que não conseguem alcançar o desempenho exigido, quanto dos que, mediante sacrifícios, transformam toda a sua energia em força de trabalho. Configura-se em falhas que precisam urgentemente ser corrigidas para que haja o reconhecimento da correlação entre essas duas medidas (Gaulejac, 2007).

E essa constatação revela uma face da acreditação pouco explorada, pois enquanto muito se fala sobre a necessidade de maior comprometimento do trabalhador com os processos burocráticos e assistenciais de implantação da acreditação, negligencia-se os fatores relacionados ao desgaste profissional potencializados pela tensão e pressão decorrentes das cobranças constantes que geram insatisfação, estresse, ansiedade e adoecimento (Manzo, Brito \& Corrêa, 2011; Manzo, Ribeiro, Brito \& Alves, 2012; Manzo, Brito \& Alves, 2013). Nesse sentido, espera-se um olhar inovador das instituições promotoras dos padrões de qualidade na saúde, para que incluam medidas protetivas ao trabalhador e à sua saúde em suas propostas

\section{Considerações Finais}

A gestão OS, com destaque para a acreditação da ONA, carrega consigo exigências de metas a serem atingidas, normas e seguimento de protocolos, gerando, conforme percepção de seus trabalhadores, sobrecarga de atribuições e ampliação do trabalho clínico assistencial e de responsabilidades no registro documental de procedimentos, nem sempre compatíveis com as condições estruturais, físicas e psicossociais concedidas, gerando adoecimento dos mesmos. Em contrapartida, resulta em benefícios para os usuários e boas práticas de organização dos processos de trabalho. Assim, urge adequações nos padrões e exigências dos programas de qualidade, para que a saúde dos trabalhadores alcance um patamar de importância similar à dos pacientes, no campo do cuidado, das melhorias contínuas das relações trabalhistas mais justas, cooperativas, horizontais e humanizadas, e reverberem também em um meio ambiente do trabalho saudável.

Há concordância dos gestores, diante da premência na ampliação de ações promocionais à saúde e preventivas de doenças e agravos dos trabalhadores, mesmo conflitantes, com suas percepções, aos efeitos deletérios da 'acreditação' e da gestão OS, no adoecimento dos trabalhadores. Este fato pode indicar abertura para introdução de processos de horizontalização e simetria nas relações de trabalho, promotores de espaços de negociação democráticos, essenciais para tomadas de decisão equânimes, coparticipativas e efetivas na proteção à saúde do trabalhador.

Nesse sentido, surgiram sugestões de meios e processos, a curto, médio e longo prazo, que podem minimizar esses efeitos prejudiciais sobre a saúde dos trabalhadores, destacando-se: progressão na carreira e estabilidade no labor; participação dos trabalhadores na construção e revisão das metas contratuais (em que os trabalhadores são sujeitos); ações de monitoramento da situação de saúde dos trabalhadores, mediante a análise dos relatórios periódicos dos afastamento e questionários interativos (virtuais e online), preenchidos, periodicamente, pelos trabalhadores; e formação de grupos de apoio psicológico para os profissionais, além de inserção de práticas voltadas para o relaxamento e entretenimento e a criação de espaços de fala e escuta para negociação e mediação de conflitos, entre gestores e trabalhadores.

Salienta-se, em outro patamar, a canalização do estresse dos trabalhadores na cooperação coletiva, representando a força necessária para suportarem as condições adversas do trabalho. Toda essa gama de estratégias, são viáveis com justeza e 
democracia, isto é, de forma participativa, com debate de opiniões e busca do equilíbrio, onde a tríade gestor - trabalhador comunidade se beneficiem reciprocamente. Não obstante a realidade, complexa e contraditório, do mundo do trabalho, de ênfase na produtividade, competitividade, individualidade e nos processos, em prejuízo e danos ao trabalhador-cuidador, torna-se vital a incessante mobilização e luta, na busca pela saúde, sanidade e sobrevivência desses trabalhadores.

Portanto, torna-se importante recomendar a ampliação dos estudos qualitativos nessa área, isto é, buscar para além dos fatos, a percepção e os sentimentos dos trabalhadores da saúde, investigar, também, nas esferas técnica e administrativa afetas, direta ou indiretamente, à assistência aos pacientes; e ainda transcender o campo da saúde ocupacional e promover o reconhecimento e monitoramento das condição de saúde desses trabalhadores, pois as pesquisas tendem a priorizar, usualmente, os pacientes (usuários) e a melhoria dos processos voltados para o cuidado dos mesmos, omitindo quem produz o cuidado e desconhecendo sua situação, por vezes, de esgotamento profissional ou mesmo de adoecimento físico e/ou mental.

\section{Agradecimentos}

Agradeço aos participantes do estudo: trabalhadores e gestores, que se dispuseram, de forma sincera e corajosa, a compartilharem seus sentimentos e percepções, a respeito de sua rotina de trabalho.

\section{Referências}

Abini, E., Zoni, S., Parrinello, G., Benedetti, L. \& Lucchini, R. (2011). An integrated model for the assessment of stress related risk factors in health care professional. Industrial Health, 49(1), 15-23. https://doi.org/10.2486/indhealth.ms948.

Andrade, A. N. M., Albuquerque, M. A. C. \& Andrade, A. N. M. (2011). Avaliação do Nível de estresse do anestesiologista da Cooperativa de Anestesiologia de Sergipe. Revista Brasileira Anestesiologia, 61(4), 490-494. https://doi.org/10.1590/S0034-70942011000400011.

Bardin, L \& Schindler. (2010). Análise de conteúdo. (Luís Antero Reto, Trad.). Edições70.

Baruki, L.V. (2018). Riscos psicossociais e saúde mental do trabalhador: por um regime jurídico preventivo. (2a ed.). LTR.

Boldor, N.; Bar-Dayan, Y., Rosenbloom, T., Shemer, J. \& Bar-Dayan, Y. (2012). Optimism of health care workers during a disaster: a review of the literature. Emerging Health Threats Journal, 5(1), 72-70. https://doi.org/10.3402/ehtj.v5i0.7270.

Canzonieri, A. M. (2010). Metodologia da pesquisa qualitativa na saúde. Petrópolis: Vozes.

Carlini-Cotrim, B. (1996) Potencialidades da técnica qualitativa grupo focal em investigações sobre abuso de substâncias. Revista de Saúde Pública, 30 (3), 285293. http://dx.doi.org/10.1590/S0034-89101996000300013.

Carneiro, C. M. S., Silva, G. C. \& Ramos, L. F. C. (2018). Relações sustentáveis de trabalho. LTR.

Ceccim, R. B. (2005) Educação Permanente em Saúde: desafio ambicioso e necessário. Interface: comunicação, saúde, educação, 9(6), 161177. https://doi.org/10.1590/S1414-32832005000100013.

Conselho Nacional De Secretários De Saúde (2011). CONASS. A gestão do trabalho e da educação na saúde. Brasília, DF (Coleção para entender a gestão do SUS 2011, 9). http://www.conass.org.br/bibliotecav3/pdfs/colecao2011/livro_9.pdf.

Cooper, C. L. (2005) A natureza mutante do trabalho: o novo contrato psicológico e os estressores associados. In: Rossi, A.; Perrewé, P. L. \& Sauter, S. L. Stress e qualidade de vida no trabalho: perspectivas atuais da saúde ocupacional. (pp.3-8). Atlas.

Cooper, D. R \& Schindler. (2003). Método de pesquisa em administração. (7a ed.). Bookman.

Costa E Silva, V., Barbosa, P. R. \& Hortale, V. A. (2016). Parcerias na saúde: as Organizações Sociais como limites e possibilidades na gerência da Estratégia Saúde da Família. Ciência \& Saúde Coletiva 21(5), 1365-1376. https://doi.org/10.1590/1413-81232015215.23912015.

Dejours, C. (2007) A Banalização da injustiça social. (Luiz Alberto Monjardim, Trad.) (reimpressão). Editora FGV.

Ditomassi, M. A. (2012) Multi-instrument evaluation of the professional practice environment. The Journal of Nursing Administration, 42 (5), 266-272. https://doi.org/10.1097/NNA.0b013e3182480901.

Fernandes, L. E. M., Soares, G. B., Turino, F., Bussinguer, E. C. A. \& Sodré, F. (2018). Recursos Humanos em Hospitais Estaduais gerenciados por Organizações Sociais de Saúde: a lógica do privado. Trabalho, Educação e Saúde, 16(3), 955-973. http://dx.doi.org/10.1590/1981-7746-sol00140.

Ferreira, C. A. A., Neto, M. T. R., Kilimnik, Z. M. \& Santos, A. S. (2016). O contexto do estresse ocupacional dos trabalhadores da saúde: estudo bibliométrico. Revista de Gestão em Sistemas de Saúde, 5(2), 84-99. https://doi.org/10.5585/rgss.v5i2.233. 
Franco, T., Druck, G. \& Seligmann-Silva, E. (2010) As novas relações de trabalho, o desgaste mental do trabalhador e os transtornos mentais no trabalho precarizado. Revista Brasileira de Saúde Ocupacional, 35(122), 229-248. https://doi.org/10.1590/S0303-76572010000200006

Gaulejac, V. (2007). Gestão como doença social: ideologia, pode gerencialista e fragmentação social. (Vitor Stomiolo, Trad.). Ideias \& Letras, 2007.

Higashi, P., Simonetti, P., Carvalhaes, M. A. B. L., Spiri, W.C. \& Parada, C. M. G. L. (2013). Situações potencialmente geradoras de estresse para enfermeiros segundo condição de acreditação do hospital. Revista Rene, 14(6), 1141-1148. http://www.periodicos.ufc.br/rene/article/view/3728/2948.

Hung, L-M., Shi, L., Wang, H., Nie, X. \& Meng, Q. (2013). Chinese primary care providers and motivating factors on performance. Family Practice, 30(5), 576-586. https://doi.org/10.1093/fampra/cmt026.

Jorge M. J., Carvalho, F. A. \& Sales, P. R. (2014). Determinantes organizacionais do ambiente hospitalar: uma análise empírica usando microdados sobre conformidade segundo o modelo da acreditação hospitalar. Revista de Administração Hospitalar, 11 (1), 68-82. 10.21450/rahis.v11i1.1949.

Jorge, M. J., Carvalho, F. O. \& Medeiros, R. O. (2013) Esforços de inovação organizacional e qualidade do serviço: um estudo empírico sobre unidades hospitalares. Revista de Administração Pública, 47(2),327-356. https://doi.org/10.1590/S0034-76122013000200003.

Kilimnik, Z. M., Bicalho, R. F. S., Oliveira, L. C. V. \& Mucci, C. B. M. R. (2012). Análise do estresse, fatores de pressão do trabalho e comprometimento com a carreira: um estudo com médicos de uma unidade de pronto atendimento de Belo Horizonte, Minas Gerais. Revista Gestão e Planejamento, 12(3), 668-693. https://revistas.unifacs.br/index.php/rgb/article/view/2010/1863.

Lima, S. B. S. \& Erdmann, A. L. (2006). A enfermagem no processo da acreditação hospitalar em um serviço de urgência e emergência. Acta Paulista de Enfermagem, 19(3), 271-278. https://doi.org/10.1590/S0103-21002006000300003.

Macêdo, K. B., Fleury, A. D., Bueno, M. \& Pires, R. V. A. (2013) Constituição do espaço de discussão coletivo e suas vicissitudes: quatro estudos e uma reflexão. In: Merlo, A. R. C.; Mendes, A. M. \& Moraes, R. D. (Org.). O sujeito no trabalho: entre a saúde e a patologia (215-234). Curitiba: Juruá.

Manzo, B. F., Ribeiro, H. C. T. C., Brito, M. J. M. \& Alves, M. (2012) A enfermagem no processo de acreditação hospitalar: atuação e implicações no cotidiano de trabalho. Revista Latino-Americana de Enfermagem, 20(1), 1-8. https://doi.org/10.1590/S0104-11692012000100020.

Manzo, B. F, Brito, M. J. \& Alves, M. (2013) Influência da comunicação no processo de acreditação hospitalar. Revista Brasileira de Enfermagem, Brasília, 66(1), 46-51. https://doi.org/10.1590/S0034-71672013000100007.

Manzo, B. F., Brito, M. J. \& Corrêa, A. R. (2012). Implicações do processo de Acreditação Hospitalar no cotidiano de profissionais de saúde. Revista da Escola de Enfermagem da USP, 46(2), 388-394. https://doi.org/10.1590/S0080-62342012000200017.

Mendanha, M. C., Bernardes, P. F. \& Shiozawa, P. (2018). Desvendando o burn-out: uma análise interdisciplinar da Síndrome do Esgotamento Profissional. São Paulo: LTR.

Mezomo, J. C (2001). Gestão da qualidade na saúde: princípios básicos. Manole.

Minayo, M. C. S. (2012) Análise qualitativa: teoria, passos e fidedignidade. Ciênc. saúde coletiva, 17(3), 621-626.

Novaes, H. M. D. (2000) Avaliação de programas, serviços e tecnologias em saúde. Revista de Saúde Pública, 34(5), 547-559. https://doi.org/10.1590/S003489102000000500018

Organização Nacional De Acreditação (2020). Manual Brasileiro de Acreditação. In: ONA 20 anos. ONA, 2020. https://www.ona.org.br/20anos/manualbrasileiro-de-acreditacao/.

Pacheco, H. F., Júnior, G. D. G., Santos, F. A. S., Ferreira, S. C. C. F. \& Leal, E. M. M. (2016) Organizações sociais como modelo de gestão da assistência à saúde em Pernambuco, Brasil: percepção de gestores. Interface 20(58), 585-589. https://doi.org/10.1590/1807-57622015.0338.

Paiva, K. C. M., Gomes, M. A. N. \& Helal, D. H. (2015). Estresse ocupacional e síndrome de burnout: proposição de um modelo integrativo e perspectivas de pesquisa junto a docentes do ensino superior. Gestão \& Planejamento, 16(3), 285-309. https://revistas.unifacs.br/index.php/rgb/article/view/3570.

Panizzon C., Luz A. M. \& Fensterseifer, L. M. (2008) Estresse da equipe de enfermagem de emergência. Revista Gaúcha de Enfermagem, 29(3), 391-399. https://seer.ufrgs.br/RevistaGauchadeEnfermagem/article/view /6759/4065.

Paraízo, C. B. \& Bégin, L. (2020) Ética organizacional em ambientes de saúde. Ciência \& Saúde Coletiva, 25(1), 251-259. https://doi.org/10.1590/141381232020251.28342019 .

Pedroso, B. \& Pilatti, L. A. (2010) Avaliação de indicadores na área da saúde: qualidade de vida e suas variantes. Revista Eletrônica FAFIT/FAFIC, 1 (1), 1-9. http://www.fafit.com.br/revista/index.php/fafit/article/viewFile/2/2.

Peres, C., Silva, R. F \& Barba, P. C. S. (2016). Desafios e potencialidades do processo de educação permanente em saúde. Trabalho, Educação e Saúde, 14(3), 783-801. https://doi.org/10.1590/1981-7746-sol00016.

Portaria $n^{\circ} 198$ GM/MS, de 13 de fevereiro de 2004. Institui a Política Nacional de Educação Permanente em Saúde como estratégia do Sistema Único de Saúde para a formação e o desenvolvimento de trabalhadores para o setor e dá outras providências. Ministério da Saúde. http://bvsms.saude.gov.br/bvs/saudelegis/gm/2017/MatrizesConsolidacao/comum/13150.html.

Potocka, A. (2012). Questionnaires for assessment of work-related psychosocial hazards-a review of diagnostic tools. Medycyna Pracy, 63(2), 237-50. http://weba-ebscohost.ez34.periodicos.capes.gov.br/ehost/pdfviewer/pdfviewer? vid=1\&sid=2ab9d261-72ae-4f4a-b55a-ab8b9ef3f312\%40sdc-v-sessmgr01.

Santos, E. J. \& Lacaz, F. A. C. (2013). Análise Preliminar Sobre Plano De Carreiras, Cargos e Salários e suas Repercussões na Gestão do Trabalho em Saúde em dois Municípios da Grande São Paulo. In: Congresso Brasileiro De Política, Planejamento e Gestão Em Saúde. 
Research, Society and Development, v. 10, n. 11, e81101119437, 2021

(CC BY 4.0) | ISSN 2525-3409 | DOI: http://dx.doi.org/10.33448/rsd-v10i11.19437

Seligmann, E. (2016). Saúde Mental relacionada ao Trabalho: as visões teóricas sob a pressão da precarização. In Organização do Trabalho e Adoecimento: uma visão interdisciplinar (pp. 171-198). Editora da PUC Goiás.

Silva, A. H. \& Fossá, M. I. T. (2015) Análise de conteúdo: exemplo de aplicação da técnica para análise de dados qualitativos. Qualitas Revista Eletrônica, 17 (1), 1-14. http://revista.uepb.edu.br/index.php/qualitas/article/view/2113/1403.

Simões F. I. W. \& Hashimoto, F. (2013) Adoecimento no trabalho: um estudo de caso. Revista Laborativa, 2 (2), $73-85$. https://repositorio.unesp.br/bitstream/handle/11449/126925/ISSN2316-6746-2013-02-02-73-85.pdf?sequence=1\&isAllowed=y.

Sobral, R. C., Stephan, C., Bedin-Zanatta, A. \& De-Lucca, S.R. (2018). Burnout e a organização do trabalho na Enfermagem. Revista Brasileira de Medicina do Trabalho, 16(1), 44-52. 10.5327/Z1679443520180127.

Tanaka, O. \& Melo, C. (2004) Reflexões sobre a avaliação em serviços de saúde e a adoção das abordagens qualitativa e quantitativa. In: Bosi, M. L. M. \& Mercado, F. J. (Org.). Pesquisa qualitativa de serviços de saúde (pp. 121-136). Vozes.

Turato, E. R. (2005). Métodos qualitativos e quantitativos na área de saúde: definições, diferenças e seus objetos de pesquisa. Revista de Saúde Pública, 39 (3), 507-14. https://doi.org/10.1590/S0034-89102005000300025. 